\title{
Simultaneous Estimation of Levetiracetam and its Preservatives In Oral Liquid Dosage form by Rp-Hplc Method
}

\author{
A Caroline Grace ${ }^{1 *}$, T Prabha1 , M Jagadeeswaran ${ }^{1}$, K Srinivasan² ${ }^{2}$ T Sivakumar ${ }^{2}$ \\ ${ }^{1}$ Department of Pharmaceutical Analysis, Nandha college of Pharmacy and Research Institute, Erode 638 052, Tamilnadu, India. \\ ${ }^{2}$ Department of Pharmaceutical Chemistry, Nandha college of Pharmacy and Research Institute, Erode 638 052, Tamilnadu, India.
}

Received: March 04, 2016; Accepted: March 30, 2016; Published: April 15, 2016

*Corresponding author: A Caroline Grace, Department of Pharmaceutical Analysis, Nandha college of Pharmacy and Research Institute, Erode 638 052, Tamilnadu, India, Mobile No: +919788880757;Email: carodani24@gmail.com

\begin{abstract}
A rapid, simple, sensitive and accurate RP-HPLC method was developed and validated for simultaneous estimation of Levetiracetam and its preservatives (Methyl paraben and Propyl paraben) in oral liquid dosage form. The chromatographic separations were achieved on a Zorbax CN column $(250 \times 4.6 \mathrm{~mm}$ inner diameter, $5 \mu \mathrm{m})$ using a mobile phase consisting of orthophosphoric acid buffer (pH 4.6) acetonitrile $(75: 25 \mathrm{v} / \mathrm{v})$ at a flow rate of $1.0 \mathrm{~mL} / \mathrm{min}$ with UV detection at $210 \mathrm{~nm}$. This system produced sharp peaks with good resolution, minimum tailing and satisfactory retention time for Levetiracetam, Methyl paraben and Propyl paraben were found to be 4.601, 9.905 and 19.291 respectively.
\end{abstract}

The method was validated as per USP guidelines which include accuracy, precision, linearity and range, robustness specificity and ruggedness. The described method was linear over the range of 30$90 \mu \mathrm{g} / \mathrm{ml}$ for Levetiracetam with $\mathrm{r}^{2}$ of 0.9999 and $60-180 \mu \mathrm{g} / \mathrm{ml}$ for Methyl paraben with $\mathrm{r}^{2} 0.9997$ and 20-60 $\mu \mathrm{g} / \mathrm{ml}$ for Propyl paraben with $\mathrm{r}^{2} 0.9999$. The average recovery of the method was $98.2 \%$, $99.3 \%$ and $98.7 \%$ for Levetiracetam, Methyl paraben and Propyl paraben respectively.

The developed method is repeatable and selective for the analysis of Levetiracetam and its preservatives in oral liquid dosage form. Hence the method could be successfully applied for routine analysis. The developed method could also applicable in quality control testing in analysis of oral liquid dosage form and in process testing.

Keywords: Levetiracetam; RP-HPLC; Oral Liquid Dosage Form; Preservatives

\section{Introduction}

Levetiracetam (LEV) is a novel anti-epileptic agent. The chemical name of LEV, a single enantiomer is $(-)-(\mathrm{S})$ - $\alpha$-ethyl2-oxo-1-pyrrolidine acetamide. [1] The chemical structure of LEV is shown in Figure 1. Its molecular formula is $\mathrm{C}_{8} \mathrm{H}_{14} \mathrm{~N}_{2} \mathrm{O}_{2}$ and its molecular weight is 170.21 . It is chemically unrelated with existing anti-epileptic drugs, differing in structure and pharmacology [2, 3]. This is a structural analogue of piracetam, which binds to a synaptic vesicle protein SV2A and is believed to impede nerve conduction across synapses. The exact mechanism by which Levetiracetam shows its antiepileptic effect is still unknown. However, it is believed that it binds to a synaptic vesicle protein, thus slowing down nerve conduction across synapses [4]. Levetiracetam is approved by the U.S. Food and Drug Administration as an adjunct in partial on set seizures, myoclonic seizures and primary generalized tonic-clonic seizures and mono therapy for partial seizures with or without secondary generalization. Levetiracetam has possible benefits for other psychiatric and neurologic conditions 4 such as Tourette syndrome, autism, and anxiety disorders $[4,5]$.

The extensive literature survey revealed few methods are developed to estimate the drug Levetiracetam in raw material, tablets and in biological fluids using UV [5-7], RP-HPLC [2,8-18], LC-MS [19-21], Capillary electrophoresis [22], UPLC [23,24], Gas Chromatography [25,26] and HPTLC [27]. However, there is no method developed yet for the simultaneous estimation of Levetiracetam and its preservatives by RP-HPLC in oral liquid dosage forms. Hence, the present work is aimed to develop a new method for Levetiracetam and its preservatives (Methyl paraben and Propyl paraben) by RP-HPLC in oral liquid dosage form and validation of the developed method.

\section{Experimental methods}

\section{Chemicals and Reagents}

Levetiracetam standard drug, Methyl Paraben and Propyl Paraben were obtained as gift samples from Hetero research

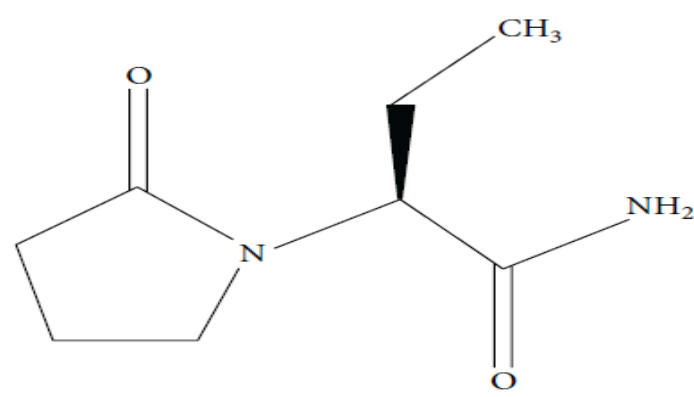

Figure 1: Chemical structure of Levetiracetam. 
labs. Formulation Keppra-1 ml oral solution was purchased from local market. Acetonitrile, Water and Methanol (HPLC grade) from Merck, orthophosphoric acid (AR) from S.D.Fine chemicals were used.

\section{Instruments}

Waters HPLC system equipped with waters separation module 2695 and auto sampler was employed for analysis. The chromatographic data was acquired by using empower 2 software. Zorbax CN, $(250 \times 4.6 \mathrm{~mm}), 5 \mu \mathrm{m}$ column was used for separation. Lab India UV 3000/ UV win- Double beam UV-VISIBLE Spectrophotometer, Ultra sonicator- MAN-009Systronics, Gelman science vaccum lamp, $\mathrm{pH}$ meter- $\mu \mathrm{pH}$ system 361- Systronics were also used.

\section{Selection of Wave Length}

In setting up the conditions for development of the assay method, the choice of detection was based on the scanned absorption spectrum for Levetiracetam, Methyl paraben (MP) and Propyl paraben (PP). The U.V spectrum of Levetiracetam, Methyl paraben and Propyl paraben (Figure 2a, 2b, 2c) were obtained separately by scanning the sample solution in methanol over the wavelength range $200-400 \mathrm{~nm}$ against the blank.

\section{HPLC Conditions}

A mixture of orthophosphoric acid buffer ( $\mathrm{pH} 4.6)$ and acetonitrile $(75: 25, \mathrm{v} / \mathrm{v})$ was employed as a mobile phase. Flow rate $1.0 \mathrm{~mL} / \mathrm{min}$, injection volume $20 \mu \mathrm{l}$ and the Detection wavelength was $210 \mathrm{~nm}$.

\section{Standard Solutions}

Stock standard solution was prepared by dissolving $50 \mathrm{mg}$ Levetiracetam, $50 \mathrm{mg}$ Methyl paraben and $50 \mathrm{mg}$ propyl paraben separately in $100 \mathrm{ml}$ mobile phase.

Working standard solution was prepared to get a final concentration of $60 \mu \mathrm{g} / \mathrm{ml}$ Levetiracetam, $120 \mu \mathrm{g} / \mathrm{ml}$ Methyl paraben and $40 \mu \mathrm{g} / \mathrm{ml}$ propyl paraben.

\section{Sample Solution}

Weigh and transfer accurately about $5 \mathrm{ml}$ of Levetiracetam oral solution into $100 \mathrm{ml}$ clean dry volumetric flask. Dissolve and dilute to volume with mobile phase and filter. Transfer $2 \mathrm{ml}$ of above filtered solution into $100 \mathrm{ml}$ volumetric flask and dilute to volume with mobile phase and mix.

\section{Procedure for Estimation}

$20 \mu$ l of blank, placebo, standard preparation (5times), and sample preparation were injected into the chromatographic system separately. Chromatogram was recorded and peak responses were measured. The placebo chromatogram was examined for any extraneous peaks observed in the chromatogram of sample preparation. The concentration of drug was calculated by using the following formula.

Concentration of drug $=$

$$
\frac{A_{T}}{A_{s}} X \frac{W_{S}}{100} \quad X \frac{5}{100} \quad X \frac{100}{W_{T}} \quad X \frac{50}{5} X \frac{P}{100} \quad X \quad A
$$

Where

$\mathrm{A}_{\mathrm{T}}=$ Area count of Drug peak in sample solution.

$A_{s}=$ Average area count of five replicate injections for drug

$\mathrm{W}_{\mathrm{S}}=$ Weight of drug working standard taken in $\mathrm{mg}$

$\mathrm{W}_{\mathrm{T}}=$ Weight of sample taken in $\mathrm{mg}$

$\mathrm{P}=$ Purity of drug working standard used

$\mathrm{A}=$ weight per $\mathrm{ml}$ of solution .

\section{Results and Discussion}

\section{Method Development and Optimization of HPLC Conditions}

The HPLC conditions were optimized by using trials with different columns, several mobile phase compositions, flow rate and $\mathrm{pH}$. The mobile phase containing orthophosphoric acid buffer $(\mathrm{pH} 4.6)$ and acetonitrile $(75: 25, \mathrm{v} / \mathrm{v})$, Zorbax CN $(250 \times 4.6 \mathrm{~mm}) 5 \mu \mathrm{m}$ column at a flow rate of $1.0 \mathrm{ml} / \mathrm{minute}$ and $210 \mathrm{~nm}$ wavelength detection was selected because it gave sharp peaks with good resolution, minimum tailing and satisfactory retention time.

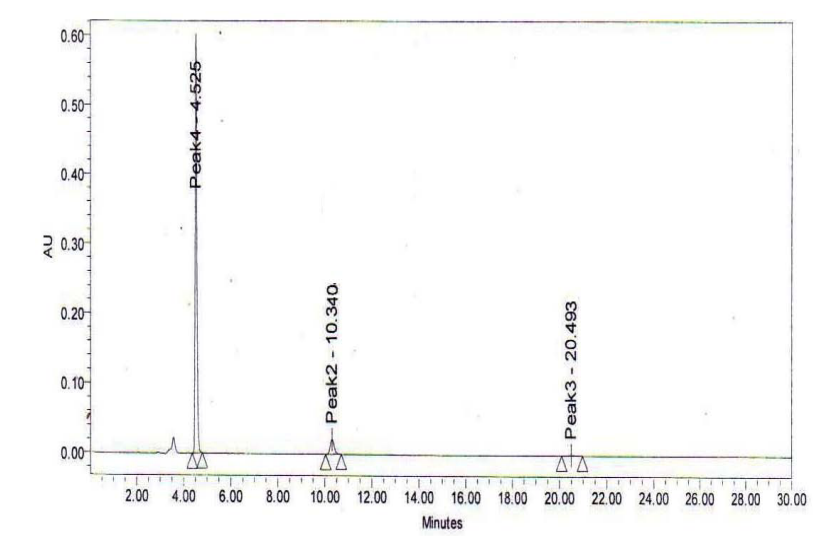

Figure 2: Standard drug chromatogram.

\section{Method Validation}

The validation of the current method was performed which include accuracy, precision, linearity and range, robustness, specificity and ruggedness [28-32].

\section{System Suitability}

The system suitability parameters were evaluated with the help of standard chromatogram which is shown in Figure 2. Plate counts $(\mathrm{N})$, Tailing factor $(\mathrm{T})$ and resolution $\left(\mathrm{R}_{\mathrm{s}}\right)$ are determined from replicate injection of standard compared with method specification Levetiracetam and its preservatives solutions were prepared and injected. All the system suitability parameters were within the acceptance criteria, which is listed in Table 1.

\section{Accuracy}

Accuracy is determined by applying the method in triplicate to sample to which known amounts of analyte have been added 
at about $50 \%, 100 \% \& 150 \%$ of the test concentration, i.e. ( 30 , 60 and $90 \mu \mathrm{g} / \mathrm{mL})$ of LEV, (60, 120 and $180 \mu \mathrm{g} / \mathrm{mL})$ of MP and $(20,40$ and $60 \mu \mathrm{g} / \mathrm{mL})$ of PP. The recovery studies were carried out with three injections in each concentration. The accuracy is then calculated from the test results as the percentage of analyte recovered by the assay which is presented in Table 2 .

\section{Precision}

The precision of the developed method was studied by performing intraday and interday variations. Intraday variation was determined by six replicate injections of standard in the same day and the interday was determined in six consecutive days. The precision was evaluated by calculating the \%RSD of peak areas of six replicate injections of LEV, MP and PP. The \% RSD of intraday precision was found to be $0.54,0.55$ and 0.81 for LEV, MP and PP respectively and the \% RSD of interday precision was found to be $0.68,0.74$ and 0.98 for LEV, MP and PP respectively. The lower \% RSD values showed excellent precision of the method.

\section{Linearity}

Five different concentrations of standard solutions were selected to demonstrate the linearity of the method, i.e. 30-90 $\mu \mathrm{g} / \mathrm{mL}$ for LEV, $60-180 \mu \mathrm{g} / \mathrm{mL}$ for MP and 20-60 $\mu \mathrm{g} / \mathrm{mL}$ for PP. The calibration curve was plotted using concentration versus peak area. An excellent linearity was obtained with correlation coefficient value 0.9999, 0.9997 and 0.9999 for LEV, MP and PP respectively.

\section{Robustness}

The robustness was evaluated by making slight variations in the optimized conditions such as mobile phase composition, $\mathrm{pH}$ of mobile phase, flow rate and temperature. The results obtained (Listed in Table 3) after the small deliberate changes in the method parameters has proven that the developed method is robust.

\section{Specificity}

The specificity of the proposed method was demonstrated by interference study. It was found that presence of some common exicipients did not cause any interferences at the retention time of LEV, MP and PP (Figure 3). Thus the developed method can be successfully applied for simultaneous determination of LEV, MP and PP in oral liquid dosage form.

\section{Ruggedness}

Ruggedness (Intermediate precision) of the method was evaluated by analyzing six samples by two analysts in the same laboratory by using different HPLC systems. From the Ruggedness data, the \%RSD of the peak area of LEV, MP and PP were found to be $0.67,0.74,0.98$ and $0.53,0.55,0.81$ for the analyst 1 and 2 respectively, which is well within the acceptance criteria indicating that the present method is rugged.

\section{LOD and LOQ}

LOD and LOQ were calculated by using the standard deviation of the regression line of the calibration curve and its slope. The

\begin{tabular}{|c|c|c|c|}
\hline Parameters & Levetiracetam & Methyl Paraben & Propyl Paraben \\
\hline Resolution & & 4.5 & 8.5 \\
\hline Tailing factor & 1.06 & 1.28 & 1.1 \\
\hline $\begin{array}{l}\text { Number of } \\
\text { theoretical } \\
\text { plates }\end{array}$ & 13664 & 17740 & 18436 \\
\hline $\begin{array}{l}\text { Retention time } \\
\text { (min) }\end{array}$ & 4.68 & 9.95 & 19.29 \\
\hline
\end{tabular}

\begin{tabular}{|c|c|c|c|c|}
\hline$\%$ of drug added & $\begin{array}{c}\text { Spiked } \\
\text { conc. } \\
(\mu \mathrm{g} / \mathrm{mL})\end{array}$ & $\begin{array}{c}\text { *Recovered } \\
\text { conc. }(\mu \mathrm{g} / \\
\mathrm{mL})\end{array}$ & $\begin{array}{c}* \% \\
\text { Recovery }\end{array}$ & *\% RSD \\
\hline Levetiracetam $50 \%$ & 30 & 29.41 & 98.06 & 0.469 \\
\hline Levetiracetam $100 \%$ & 60 & 59.08 & 98.46 & 0.213 \\
\hline Levetiracetam $150 \%$ & 90 & 88.21 & 98.09 & 0.163 \\
\hline Methyl Paraben 50\% & 60 & 59.41 & 99.03 & 0.162 \\
\hline Methyl Paraben 100\% & 120 & 119.56 & 99.66 & 0.04 \\
\hline Methyl Paraben 150\% & 180 & 178.34 & 99.08 & 0.161 \\
\hline Propyl Paraben $50 \%$ & 20 & 19.70 & 98.49 & 0.538 \\
\hline Propyl Paraben $100 \%$ & 40 & 39.48 & 98.69 & 0.375 \\
\hline Propyl Paraben 150\% & 60 & 59.39 & 98.99 & 0.222 \\
\hline
\end{tabular}

Table 3: Robustness of the proposed method

\begin{tabular}{|c|c|c|c|c|}
\hline \multirow[b]{2}{*}{ Factor } & \multirow[b]{2}{*}{ Level } & \multicolumn{3}{|c|}{ Peak area, \%RSD $(n=3)$} \\
\hline & & Levetiracetam & $\begin{array}{c}\text { Methyl } \\
\text { paraben }\end{array}$ & $\begin{array}{c}\text { Propyl } \\
\text { paraben }\end{array}$ \\
\hline \multirow{3}{*}{$\begin{array}{c}\text { Ratio of } \\
\text { acetonitrile } \\
\text { in the mobile } \\
\text { phase }\end{array}$} & 23 & $3276946,0.656$ & $\begin{array}{c}3450731, \\
0.772\end{array}$ & $\begin{array}{c}273318 \\
0.909\end{array}$ \\
\hline & 25 & $3087346,0.839$ & $\begin{array}{c}3241701, \\
0.828\end{array}$ & $\begin{array}{c}261227 \\
0.882\end{array}$ \\
\hline & 27 & $2799809,1.201$ & $\begin{array}{c}2866337 \\
1.039\end{array}$ & $\begin{array}{c}236391 \\
1.474\end{array}$ \\
\hline \multirow{3}{*}{$\begin{array}{l}\mathrm{pH} \text { of the } \\
\text { mobile phase }\end{array}$} & 4.4 & $3281432,0.472$ & $\begin{array}{c}3678641, \\
0.462\end{array}$ & $\begin{array}{c}270626 \\
0.534\end{array}$ \\
\hline & 4.6 & $3087346,0.839$ & $\begin{array}{c}3241701, \\
0.828\end{array}$ & $\begin{array}{c}261227 \\
0.882\end{array}$ \\
\hline & 4.8 & $3074448,1.028$ & $\begin{array}{c}2911662 \\
1.089\end{array}$ & $\begin{array}{c}248484 \\
1.070\end{array}$ \\
\hline \multirow{3}{*}{ Flow rate } & 0.8 & $3281623,0.493$ & $\begin{array}{c}3515152 \\
0.467\end{array}$ & $\begin{array}{c}304380 \\
0.544\end{array}$ \\
\hline & 1.0 & $3087346,0.839$ & $\begin{array}{c}3241701, \\
0.828\end{array}$ & $\begin{array}{c}261227 \\
0.882\end{array}$ \\
\hline & 1.2 & $2777980,1.16$ & $\begin{array}{c}2703662 \\
1.26\end{array}$ & $\begin{array}{c}232058 \\
1.31\end{array}$ \\
\hline \multirow{3}{*}{ Temperature } & $25^{\circ} \mathrm{C}$ & $3368998,0.595$ & $\begin{array}{c}3636370 \\
0.599\end{array}$ & $\begin{array}{c}256101 \\
0.624\end{array}$ \\
\hline & Ambient & $3087346,0.839$ & $\begin{array}{c}3241701, \\
0.828\end{array}$ & $\begin{array}{c}261227 \\
0.882\end{array}$ \\
\hline & $30^{\circ} \mathrm{C}$ & $2653982,1.283$ & $\begin{array}{c}2870714, \\
1.130\end{array}$ & $\begin{array}{c}2870714, \\
1.130\end{array}$ \\
\hline
\end{tabular}


LOD values were found to be $0.937,1.612,0.077 \mu \mathrm{g} / \mathrm{mL}$ for $\mathrm{LEV}$, MP and PP respectively. The LOQ values were found to be 2.841, $4,887,0.234 \mu \mathrm{g} / \mathrm{mL}$ for LEV, MP and PP respectively.

\section{Application of the Method for Estimation of LEV in Marketed Oral Liquid Dosage Form}

Using the proposed HPLC method, the determination of LEV in its commercial oral liquid dosage form was carried out. Satisfactory results were obtained, which are in good agreement with the label claim. The results are shown in Table 4.

\section{Conclusion}

A simple, specific, reliable method was developed for simultaneous estimation of Levetiracetam and its preservatives in marketed oral liquid dosage form. The method offers good resolution between the proposed components within a suitable analysis time. Based on the results obtained, it was found that the developed method is accurate, precise and sensitive. The proposed method has an advantage over the published methods for analyzing Levetiracetam in presence of the preservatives used in commercial formulation. Therefore the applied method could be conveniently adopted for the routine quality control analysis of Levetiracetam and its preservatives from its oral liquid dosage form.

\begin{tabular}{|c|c|c|c|c|c|c|c|}
\hline Drug & $\begin{array}{l}\text { Label } \\
\text { claim }\end{array}$ & $\begin{array}{c}\text { Injection } \\
\text { No }\end{array}$ & $\begin{array}{l}\text { Peak } \\
\text { Area }\end{array}$ & $\begin{array}{c}\text { Amount } \\
\text { found } \\
\text { (mg/ } \\
\mathrm{mL} \text { ) }\end{array}$ & \% Assay & $\begin{array}{c}\text { Mean \% } \\
\text { Assay }\end{array}$ & $\%$ RSD \\
\hline \multirow{2}{*}{$\begin{array}{l}\text { Levetiracetam } \\
\text { oral Solution }\end{array}$} & \multirow{2}{*}{$\begin{array}{c}100 \mathrm{mg} / \\
\mathrm{mL}\end{array}$} & 1 & 3089267 & 99.97 & 100.06 & \multirow{2}{*}{100.02} & \multirow{2}{*}{0.041} \\
\hline & & 2 & 3086798 & 99.89 & 99.98 & & \\
\hline
\end{tabular}

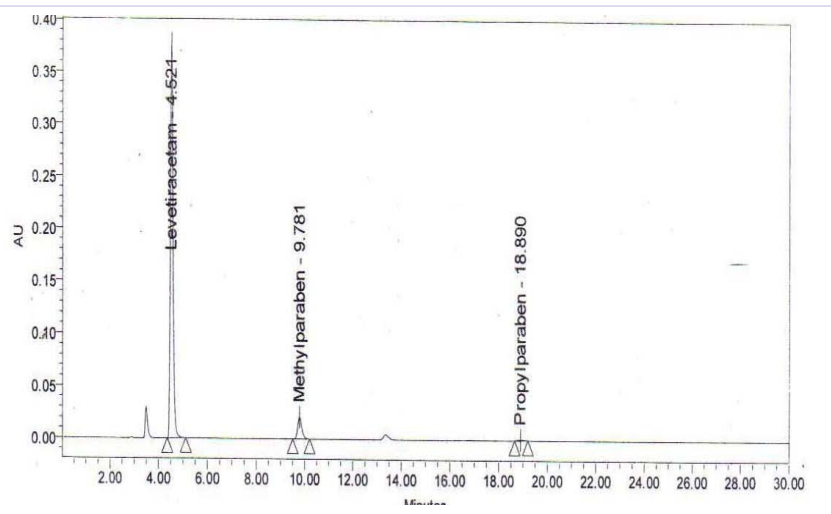

Figure 3: Chromatogram for Specificity.

\section{References}

1. M J O’Neil, A Smith, P E Heckelman, J R Obenchain Jr. The Merck Index An Encyclopedia of Chemicals, Drugs, and Biologicals. $13^{\text {th }}$ Edition. Merck \& Co., Inc., Whitehouse Station, NJ, USA; 2001. p.256-259, 978.

2. Jignesh S Shah, G Vidyasagar and H Barot. Stability indicating RP-HPLC method for estimation of levetiracetam in pharmaceutical formulation and application to pharmacokinetic study. Der Pharmacia Sinica 2012; 3 (5): 576-589

3. Keppra®, product information 2009 [online]. Available from: http:// www.keppra.com/pc/home/default.asp.
4. Martindale: The complete drug reference. 36 th edition. Pharmaceutical press, Lambeth High Street, London; 2009. p.488-489.

5. Panchumarthy Ravisankar, A Niharika, H Anusha, V Himaja, S K Afzal Basha. A simple validated UV spectrophotometric method for quantitative analysis of Levetiracetam in pharmaceutical dosage form. Indian Journal of Research in Pharmacy and Biotechnology (IJRPB). 2015;3(5):380-385

6. M Lohita, S Shakirbasha, T Edukondalu, S Vijayaraj, P Jayapreethi, K Swetha. Development and Validation of Area under the Curve and first derivative methods for the Estimation of Levetiracetam in Bulk and Tablet Dosage Form by using UV Spectrophotometry. Journal of Pharmaceutical and Biomedical Analysis Letters (JPBMAL). 2014;2(2):134-140.

7. Ch Muralikrishna, G Ramu, A Bikshambabu, S Venkata rao and C Rambabu. Spectrophotometric Determination of Levetiracetam by Developing Coloured Complexes with 2-Chlorophenylhydrazine and Anthranilic Acid. Asian Journal of Chemistry. 2012; 24(4):1855-1857.

8. M Krishna Chaitanya Prasad, G Vidhya Sagar, P Sudhakar. Stability indicating RP HPLC method for determination of levitiracetam in pharmaceutical formulation. Indian Journal of Pharmaceutical and Biological Research (IJPBR). 2013; 1(4):45-54.

9. Muhammad Usman, Hafsa Bibi, Muhammad Tariq Khalil, Altaf Hussain, Aisha Siddiqua, Javeid Iqbal. Estimation of Levetiracetam in Bulk and Pharmaceutical Dosage Form with a Newly Developed and Validated RP-HPLC Method. Research Journal of Recent Sciences. 2013;2(5):6870.

10. Farhan Ahmed Siddiqui, Nawab Sher, Nighat Shafi. Development of New Method for Simultaneous Analysis of Piracetam and Levetiracetam in Pharmaceuticals and Biological Fluids: Application in Stability Studies. BioMed Research International. 2014;1-8. doi. org/10.1155/2014/758283.

11. P Nagaraju, G Indira Priyadarshini and SCHVSS. Appaji. Development and Validation of Novel HPLC Method for Estimation of Levetiracetam in Pharmaceutical Formulations. International journal of pharmaceutical and chemical sciences. 2014;3(2):522-527.

12.A Lakshmana Rao, V Naga Jahnavi. A Validated RP-HPLC Method for the Estimation of Levetiracetam in Bulk and Pharmaceutical Formulations. E-Journal of Chemistry. 2010;7(2):600-604.

13. Manoj G Tyagi, S Kannan, A S Manickam, JSJU Chander. A novel HPLC estimation technique for the antiepileptic Drug Levetiracetam in tablet and human Urine samples. World Journal of Pharmacy and Pharmaceutical Sciences. 2015;4(6): 1093-1099.

14. Narendra Devanaboyina, T Satyanarayana, B Ganga Rao. A novel RPHPLC method for the analysis of levetiracetam in formulations. Der Pharma Chemica. 2011;3 (6):112-117.

15.S Gopalakrishnan, B Jeyashree, A Ramalakshmi, A Chenthilnathan. Analytical method development and validation for the determination of Levetiracetam in pharmaceutical formulations by using RP-HPLC. Der Pharmacia Lettre. 2011;3(3):194-201.

16.J Valarmathy, L Samueljoshua, G Rathinavel, C Selvin Thanija, T Sivakumar. RPHPLC method development and validation for assay of levetiracetam in tablet dosage form. Research Journal of Pharmacy and Technology. 2008;1(3):395-397.

17. B M Rao, R Ravi, B Shyam Sundar Reddy, Sivakumar S, Gopi Chand I, Praveen Kumar K, Acharyulu P et al. A validated chiral LC method for the enantioselective analysis of Levetiracetam and its enantiomer R- $\alpha$-ethyl-2-oxo-pyrrolidine acetamide on amylose-based stationary phase. Journal of Pharmaceutical and Biomedical analysis. 2004;35(5): 1017-1026:doi:10.1016/j.jpba.2004.03.015. 
18. Can, Arli, Goksel. Reversed-Phase HPLC Analysis of Levetiracetam in Tablets Using Monolithic and Conventional C18 Silica Columns. Journal of AOAC International. 2010;93 (4):1077-1085.

19. Ghada M Hadad, Randa A Abdel Salam, Eman A Abdel Hameed Quantitative determination of levetiracetam in human urine using HPLC-UV and its identification by LC-ESI-MS. Journal of Liquid Chromatography \& Related Technologies. 2013;36(18):2568-2579: DOI:10.1080/10826076.2012.723091.

20. Karas K, Kuczynska J, Sienkiewicz-Jarosz H, Bienkowski P, Mierzejewski P. A Simple Bioanalytical Method for the Quantification of Levetiracetam in Human Plasma and Saliva. Journal of Chromatography separation techniques. 2015;6(7):doi:10.4172/2157-7064.1000310.

21. Madhira V N S Ramprasad, B Syama Sundar. Development and Validation of High Performance Liquid Chromatographic Method for the Determination of Levetiracetam in Human Plasma by Electospray Ionization-Mass Spectrometry. International Journal of Scientific \& Engineering Research.2014; 5(3):602-609.

22. Shihabi ZK, Oles K, Hinsdale M. Analysis of the antiepileptic drug keppra by capillary electrophoresis. Journal of Chromatography A 2003;1004 (1-2):9-12. doi.org/10.1016/S0021-9673(03)00716-7.

23. Parimal Patel, Mrunali M Patel, Kunti D Raskapur, Rajendra S Mehta. Development and validation of stability-indicating UPLC method for estimation of levetiracetam in bulk and pharmaceutical dosage form. Journal of Pharmacy Research. 2011; 4(12): 4495-4497.

24. E Ola'h, Gy Bacso' i, J Fekete and V K Sharma. Determination of ng/mL Levetiracetam using Ultra-High-Performance Liquid ChromatographyPhotodiode Absorbance. Journal of Chromatographic Science. 2012;50:253-258:doi:10.1093/chromsci/bmr053.
25. Nikolaou P, Papoutsis I, Dona A, Spiliopoulou C, Athanaselis S. Development and validation of a GC/MS method for the simultaneous determination of levetiracetam and lamotrigine in whole blood Journal of Pharmaceutical and Biomedical Analysis. 2015;102: 2532:doi: 10.1016/j.jpba.2014.08.034.

26. M Indupriya, R S Chandan, B M Gurupadayya, K Sowjanya. Quantitative determination of levetiracetam by Gas Chromatography using Ethyl chloroformate as a Derivatizing Reagent in pure and pharmaceutical preparation. International Journal of Pharmacy \& Technology (IJPT). 2011;3(1):1694-1701.

27. Santosh V Gandhi, Ashwini A Kadam, Madhuri M Karad. Development and validation of stability-indicating HPTLC method for Determination of levetiracetam in pharmaceutical dosage form. International Journal of Pharmacy and Pharmaceutical Sciences. 2014;6(5):121-125.

28.General Chapter 1225. Validation of compendial methods, United States Pharmacopeia 30, National Formulary 25, Rockville, Md., USA, The United States Pharmacopeial Convention. Inc. 2007.

29. USP 25-NF 20. Validation of Compendial Methods Section (1225) United States Pharmacopeal Convention, Rockville, Maryland, USA, 2002

30. International Conference on Harmonization, "Q2B: Validation of Analytical Procedures: Methodology; Availability," Federal Register 1997;62(96): 27463-27467.

31. International Conference on Harmonization. "Q2A: Text on Validation of Analytical Procedures,” Federal Register 1995;60 (40):1126011262.

32. Available from: www.fda.gov/cder/guidance/cmc3.pdf 